\title{
Study on the Depression Effect on Combustion of Sound Components by Measurement of Oxygen Concentration Change
}

\author{
${ }^{1}$ Bong-Young Kim, ${ }^{1}$ Myung-Jin Bae and ${ }^{2}$ Seong-Geon Bae \\ ${ }^{1}$ Department of Information and Telecommunication, Soongsil University, \\ 369 Sangdo-ro, Dongjak-gu, Seoul, Korea \\ ${ }^{2}$ School of Software Application, Kangnam University, Gyunggido, Korea
}

\begin{abstract}
Conflagration is a disaster caused by uncontrolled fire. The conflagration increases sharply as the suppression slows down. Therefore, conflagration should suppression as fast as possible under all circumstances. Sound fire extinguisher is being studied to maximize the efficiency of conflagration suppression. The sound fire extinguisher has the principle that the sound component resonates with the flame to depress the combustion reaction. In this study, we investigated the effect of the sound component of the sound fire extinguisher on the combustion reaction depression by measuring the oxygen concentration change in the candlelight experiment of the closed space. Combustion is a rapid oxidation phenomenon that occurs when a substance comes into contact with oxygen and the amount of combustion is closely related to the amount of oxygen. The influence of the sound component on the amount of combustion was confirmed by measuring the amount of oxygen. As a result of the experiment in study, when the sound was supplied, the amount of combustion decreased and the oxygen concentration in which the candlelight was turned off increased. This confirms that the sound component of the sound fire extinguisher has an effect of depressing the combustion reaction of the flame.
\end{abstract}

Key words: Conflagration, sound fire extinguisher, sound component, oxygen concentration, combustion reaction, depression effect

\section{INTRODUCTION}

Conflagration is a disaster caused by uncontrolled fire. According to the National Fire Agency's Conflagration Occurrence General Table for 2017, there were 44,178 cases of conflagration in Korea in 2017 , resulting in 2,197 injuries including 345 deaths and about 500 billion won of property damage. To protect people and property from conflagration, lifestyle habits that prevent conflagration are the most important. Once a conflagration occurs, it can be minimized by suppressing the conflagration as soon as possible. In the case of conflagration as the time passes, the confusion spread rate and damage area of the conflagration are rapidly increased. If it is not suppressed early, the rescue personnel will be difficult to enter the rescue. Therefore, conflagration can be said to be important in suppressing as quickly as possible (Bae et al., 2013; Sang-Hwi et al., 2017; Jung, 2017; Kim et al., 2016; Kyoung-Suet al., 2016; Eun-Young et al., 2017; Bae and Bae, 2017, Ik-Soo and Myung-Jin, 2016; Jae-Chu et al., 2007). Conflagration is mainly suppressed by using fire extinguisher and indoor extinguishment facilities and by spraying water from fire trucks. Although, existing fire extinguisher and extinguishment facilities are effective in suppressing conflagration, it is necessary to exert more effort to extinguish the efficiency as much as possible to minimize the damage of life and property. Fire extinguisher and extinguishment facilities have limitations in enhancing extinguish efficiency due to the difficulty of additional expansion operation in limited indoor areas. Sound fire extinguisher, a new method that is very different from the existing extinguish method of spraying fire extinguishing agents and water is being actively studied. Existing fire extinguisher can no longer maintain fire extinguisher ability when exhausted but sound fire extinguisher can maintain fire extinguisher ability as long as electricity is supplied. While fire extinguishers can damage facilities, the sound fire extinguisher's sound components do not damage the facility and can be used wherever it is needed. In addition, since, the extinguish method of sound fire extinguisher differs from the existing extinguish method, it can maximize the extinguish efficiency when it is operated in parallel with the existing fire extinguishing

Corresponding Author: Myung-Jin Bae, Department of Information and Telecommunication, Soongsil University, 369 Sangdo-ro, Dongjak-gu, Seoul, Korea 
facility (Kim et al., 2016; Kyoung-Su et al., 2016; Eun-Young et al., 2017, Bae and Bae, 2017; Anthony, 2012; Sang-Hyuk and Chang-Dong, 2011; Seal, 2012; Han-Woo and Yeon-Ho, 1997).

The sound component of the sound fire extinguisher is said to resonate the flame molecule, thereby, depressing the combustion reaction of the flame. In this study, we tried to confirm how much the sound fire extinguisher sound component depression combustion reaction of flame through oxygen concentration change measurement experiment.

\section{MATERIALS AND METHODS}

Principle of extinguish and principles of sound fire extinguisher: Combustion is a powerful oxidation reaction in which a substance generates heat and light due to oxygen and abrupt chemical reaction which requires combustible fuel and high temperature and oxygen supply. Most of the burning materials are Hydrocarbons $\left(\mathrm{C}_{\mathrm{n}} \mathrm{H}_{\mathrm{m}}\right)$ which when burned through the combustion process generates water $\left(\mathrm{H}_{2} \mathrm{O}\right)$ and Carbon Dioxide $\left(\mathrm{CO}_{2}\right)$, generating strong heat. The combustion chemistry of the hydrocarbon compound is given by Eq. 1:

$$
\begin{aligned}
& \mathrm{C}_{\mathrm{n}} \mathrm{H}_{\mathrm{m}}+\mathrm{O}_{2} \Rightarrow \mathrm{CO}_{2}+\mathrm{H}_{2} \mathrm{O} \text { (Complete combustion) } \\
& \mathrm{C}_{\mathrm{n}} \mathrm{H}_{\mathrm{m}}+\mathrm{O}_{2} \Rightarrow \mathrm{CO}_{2}+\mathrm{H}_{2} \mathrm{O} \text { (Incomplete combustion) }
\end{aligned}
$$

Extinguish is the principle of extinguishing to stop or eliminate at least one element of puel, high temperature, oxygen which is necessary for combustion. It can be divided into 'extinguishment by destroying', 'extinguishment by cooling' and 'extinguishment by smothering' depending on what elements are removed in extinguish. A fire extinguisher commonly found around us is mainly extinguished by extinguishment method by smothering with 'foam extinguisher', 'powder extinguisher', 'carbon dioxide extinguisher' and 'halotron extinguisher'. In the case of water spraying of fire trucks or sprinklers, fire is extinguished by extinguishment method by cooling to lower the heat by sprinkling water (Bae et al., 2013; Sang-Hwi et al., 2017; Anonymous, 2016; Jung, 2017; Kyoung-Su et al., 2016; Sang-Hyuk and Chang-Dong, 2011; Anthony, 2012; Myung-Jin, 2017; Eung-Young et al., 2017).

Defense Advanced Research Projects Agency (DARPA) has released the principles of sound fire extinguisher which hampers the flame's combustion reaction. Students at George Mason University also unveiled a sound fire extinguisher on YouTube that uses a commercially available speaker to turn the lights off. The

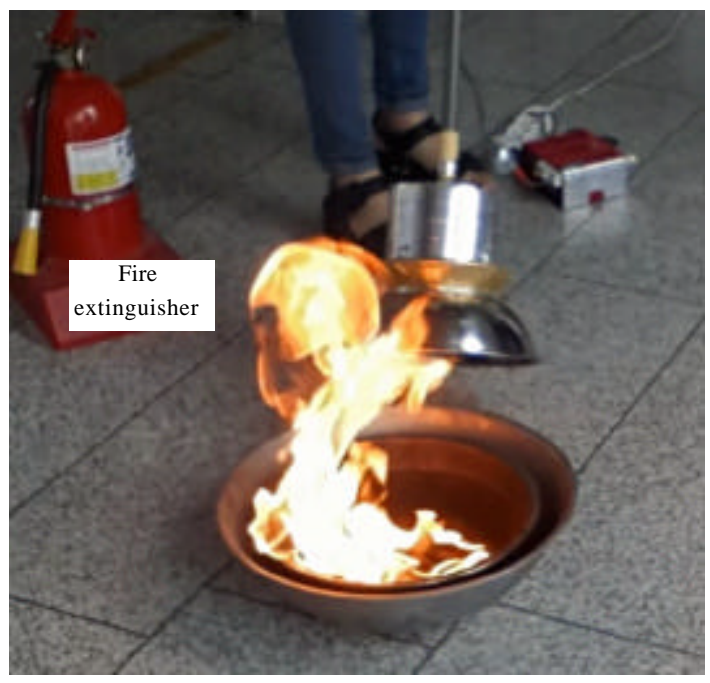

Fig. 1: Sound fire extinguisher

extinguish principle of sound fire extinguisher is "suppressing the combination of flame and oxygen" "reducing the temperature by dispersing thermal energy by enlarging flame area". In addition, sound fire extinguisher which is being studied at Sori Sound Engineering Research Institute of Soongsil University, added the principle of "concentrating sound power on flame by applying special acoustic lens". The shape of the sound fire extinguisher under study at the Sori Sound Engineering Research Institute is shown in Fig. 1 (Bae and Bae, 2017; Ik-Soo and Myung-Jin, 2016; Kang, 2008; Camm et al., 1996; Lee, 1999; Myung-Jin, 2017; Ji-Seon and Myung-Jin, 2013; Ik-Soo and Myung-Jin, 2016.

Sound fire extinguisher, first released by students at George Mason University and Defense Advanced Research Projects Agency (DARPA) showed that resonance of sound affects flame and extinguishing is possible. However, at the Sori Sound Engineering Research Institute, sound fire extinguisher is replacing existing fire extinguishers and conducting various studies to actually use them in fire fighting sites.

The material has a natural frequency depending on its characteristics and conditions. When an external force having the same frequency as its natural frequency is received, the intensity of the vibration is markedly increased. This phenomenon is called resonance. The flame consists of outer flame, inner flame and flame center and has a small arrowhead shape. When a sound similar to the natural frequency of a flame is supplied, the flame molecule resonates to broaden the structure of the flame and the shape of the arrowhead widens to the side. At this time, the temperature is lowered by dispersing the 
(a)

(b)

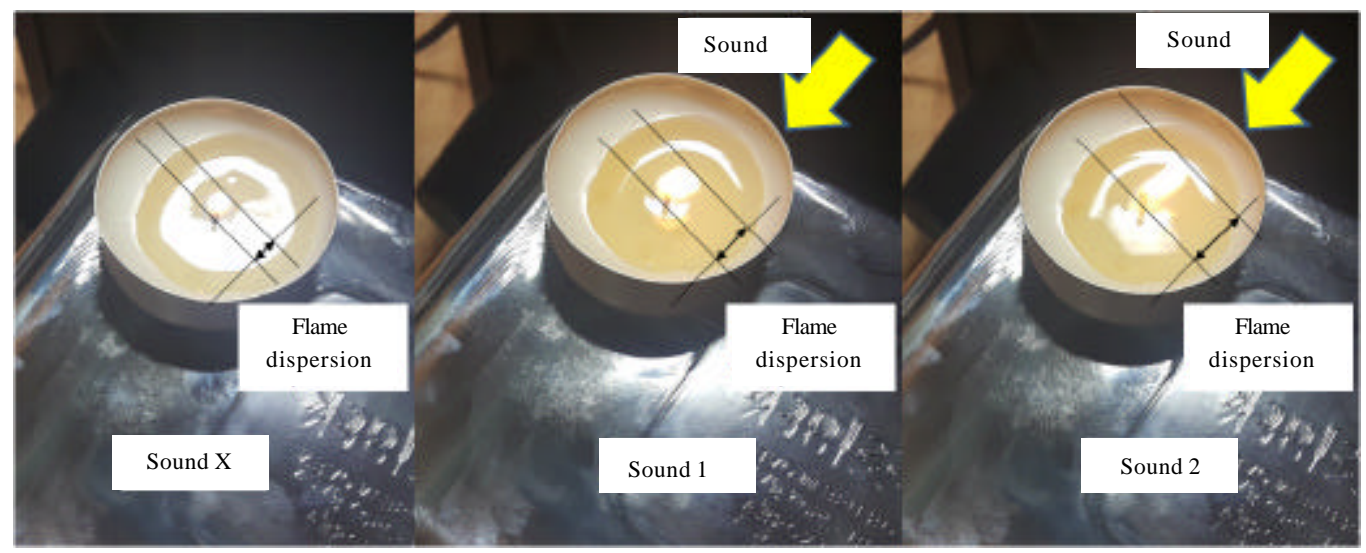

Fig. 2a-c): Flame resonance phenomenon

thermal energy of the flame. In addition, as the vibration intensity of the flame becomes clear, oxidation phenomenon in which the combustible is bonded with oxygen is suppressed. In other words, the sound component of the sound fire extinguisher resonates the flame molecule to depress the combustion reaction of the flame. Flame resonance phenomenon is shown in Fig. 2.

\section{RESULTS AND DISCUSSION}

The experiment measured the decrease time of oxygen concentration in order to know how quickly the candlelight would remove oxygen when supplying and not supplying sound in a confined space. In this candlelight experiment, we can see how much the sound component depresses the combustion reaction of the candlelight through the difference in the decrease time in the oxygen concentration. Combustion of candlelight is likely to cause errors depending on the experimental conditions including the state of the candle. Therefore, in order to maintain the same experimental environment as possible, $50 \%$ of the candles were initially tested without sound and then provided with sound. And the remaining $50 \%$ of the candles were initially tested provided with sound and then tested without sound. In addition, the reduction time of the oxygen concentration can be large at the beginning of the combustion and when the fire is turned off. Therefore, we measured the time at which the oxygen concentration decreased from $20-17 \%$ for the measurement of uniform conditions. In the experiment, a low-frequency speaker (Britz AMP BR-5100T) was used to smoothly supply a $60 \mathrm{~Hz}$ sound component to the candlelight. The 20 event-type paraffin candles were alternately covered with a $2600 \mathrm{~mL}$ glass container to measure the change until the candlelight was turned off. (a)

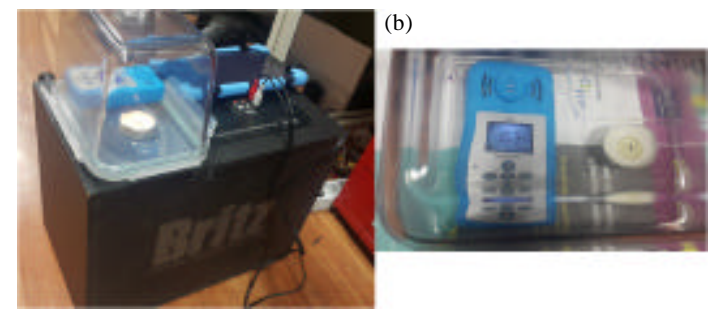

Fig. 3a, b): Measurement of oxygen concentration change

The sound was continuously supplied to $60 \mathrm{~Hz}$ pure tone sound source manufactured by Audition $\mathrm{CC}$ until the candlelight was turned off. The oxygen concentration was measured by placing a portable oxygen concentration meter (SKU-E1247) in a glass container in which the candlelight was combusted. Figure 3 shows the experimental measurement of the oxygen concentration change of the combustion of candlelight.

The sealing method used in the experiments was to use a $2600 \mathrm{~mL}$ glass vessel to ensure sufficient oxygen supply for the candlelight to combust for at least one minute without rapid oxygen restriction. Also, the volume of the sound was adjusted to allow the candlelight to combustion until the oxygen concentration became $<17 \%$ and supplied to the candlelight.

Figure 4 shows the distribution of the time taken for the oxygen concentration in the glass vessel to decrease from $20-17 \%$ by combustion of candlelight when no sound and when supplying sound. Figure 4 shows that the time required to reduce oxygen concentration was 63-96 sec (average $77 \mathrm{sec}$ ) when no sound. Also, it took $75 \sim 130 \mathrm{sec}$ (average $96 \mathrm{sec}$ ) when supplying sound. When supplying sound, the average of $19 \mathrm{sec}$ was longer than when no sound was supplied indicating that the rate of oxygen reduction was about $25 \%$ slower. 


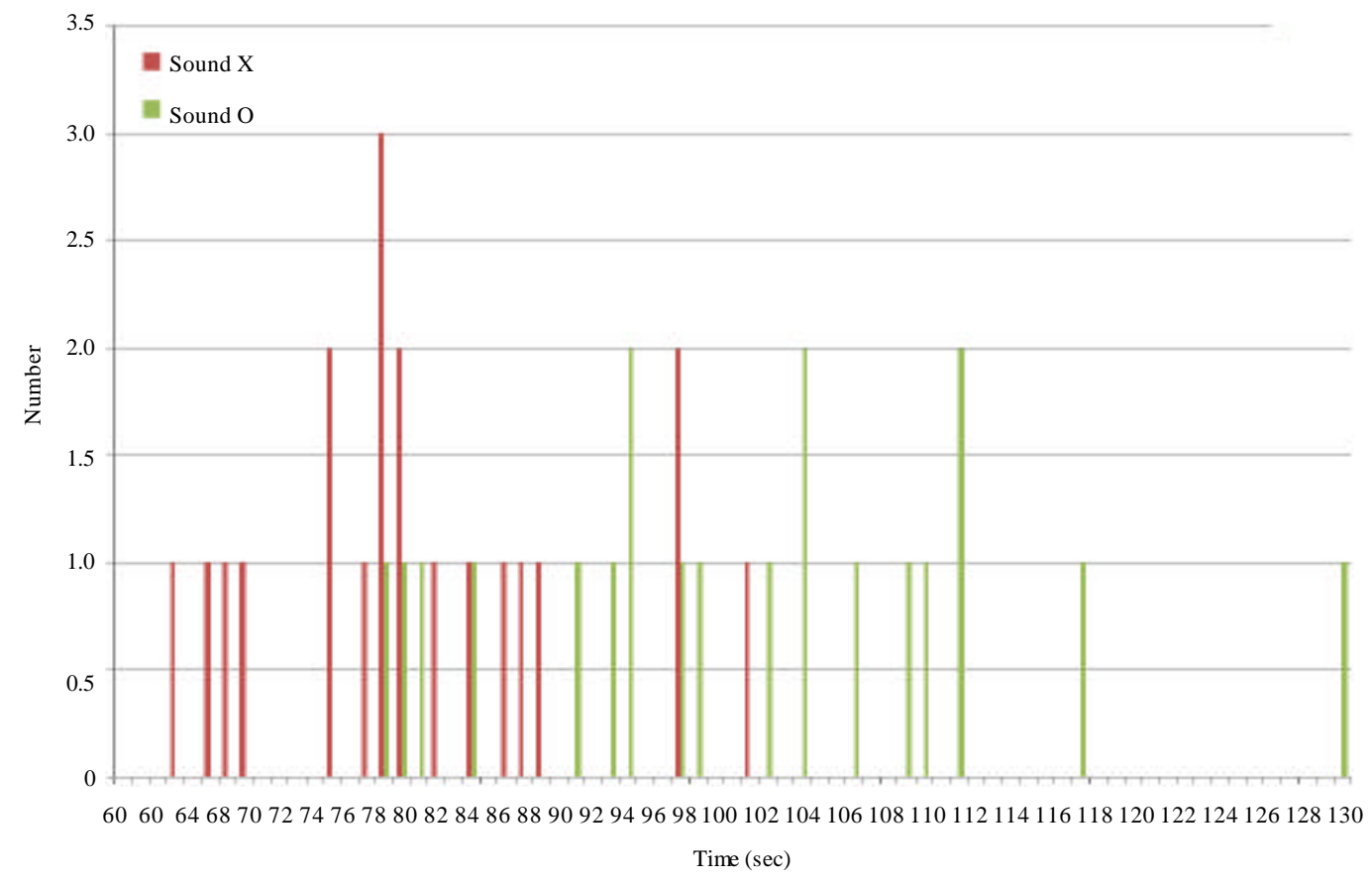

Fig. 4: Time distribution of oxygen concentration reduction $(20 \% \rightarrow 17 \%)$

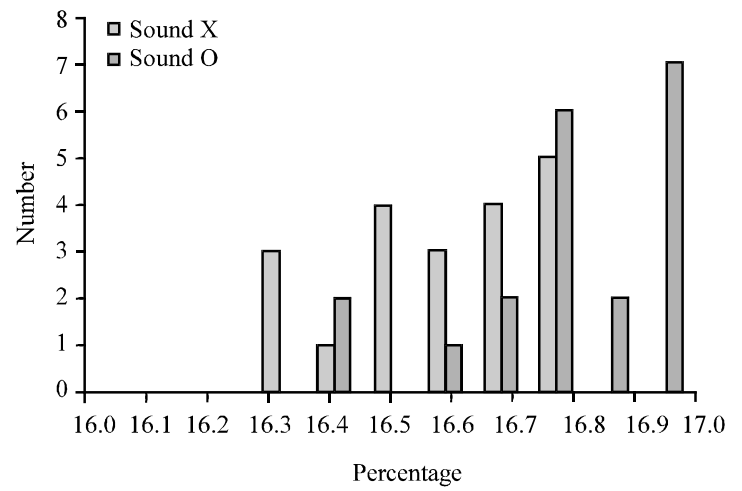

Fig. 5: Distribution of oxygen concentration by turning off the candlelight

Figure 5 shows the distribution of oxygen concentration when the candlelight is turned off in a closed laboratory environment. In Fig. 5, the candlelight is turned off at 16.3-16.8\% oxygen concentration when no sound is supplied and the candlelight is turned off at $16.4-17 \%$ when the sound is supplied. When there was no sound, candlelight was turned off at an average of $16.6 \%$. When the sound was provided, the candlelight was turned off at an average of $16.8 \%$ and the concentration difference was $0.2 \%$.

\section{CONCLUSION}

Conflagration causes a lot of human and material damage every year. Conflagration can be minimized by suppressing conflagration as quickly as possible. This is why existing fire extinguishers and extinguishment facilities are effective in suppressing conflagration but still need to improve extinguish efficiency. However, existing methods alone have limitations in increasing extinguish efficiency. Sound fire extinguisher can maximize extinguish efficiency because it is extinguished by using different principle than existing fire extinguisher. Sound fire extinguisher has the principle that flame resonates with the sound component to suppress combustion.

In this study, we investigated how the sound component depresses combustion of flame by measuring the oxygen concentration in a candlelight experiment in a closed space. In an experiment measuring the time it takes for the oxygen concentration to decrease from $20-17 \%$, the average time taken for sound supply is $77 \mathrm{sec}$ while the average time for supplying sound is $96 \mathrm{sec}$ which is about $25 \%$. Taking more time to change the oxygen concentration means that the amount of combustion has decreased. In addition, the measurement of the oxygen concentration at which the flame was turned off showed that the candlelight was off at an average of $16.6 \%$ when the sound was not supplied while the candlelight was turned off at $16.8 \%$ when the sound was supplied. These results show that the sound component of the sound fire extinguisher depresses the flame combustion reaction. The experiment was somewhat distant from the actual conflagration site and there may be an error depending on the use of the portable instrument and the state of the 
candle. However, despite the low sound power that the combustion sustains, the amount of combustion is reduced when the sound is supplied and the candlelight is turned off at a slightly higher oxygen concentration which is a significant result indicating that the sound component has a depression effect on the flame combustion reaction.

Sound fire extinguisher requires a lot of research on how to use it because it has a new extinguish principle. Through active research, sound fire extinguisher is expected to contribute to the safety of fire protection in various fields.

\section{REFERENCES}

Anonymous, 2016. Report the cause of death in 2015. Statistics Korea, Korea.

Anthony, S., 2012. DARPA creates sound-based fire extinguisher. Ziff Davis, LLC, New York, USA. http://www.extremetech.com/extreme/132859-darpacreates-sound-based-fire-extinguisher.

Bae, S., M. Kim and M. Bae, 2013. On enhancement signal using non-uniform sampling in clipped signals for LTE smart phones. Proceedings of the ICCE Berlin 2013 IEEE 3rd International Conference on Consumer Electronics Berlin (ICCE-Berlin'13), September 9-11, 2013, IEEE, Berlin, Germany, ISBN:978-1-4799-1412-8, pp: $129-130$.

Bae, S.G. and M.J. Bae, 2017. A study on recovery in voice analysis through vocal changes before and after specch using speech signal processing. Intl. J. Appl. Eng. Res., 12: 5299-5303.

Camm, A.J., M. Malik, J.T. Bigger, G. Breithardt and S. Cerutti et al., 1996. Heart rate variability: Standards of measurement, physiological interpretation and clinical use. Eur. Heart J., 17: 354-381.

Eun-Young, Y., S. Uk-Jin and B. Myung-Jin, 2017. A study on the directionality of sound fire extinguisher in electric fire. Convergence Res. Lett. Multimedia Serv. Convergent Art Hum. Sociol., 3: 1449-1452.
Han-Woo, G. and K. Yeon-Ho, 1997. Setting and analysis of arousal control standard for avoiding sleepy driving. Proc. Conf. Korean Soc. Automot. Eng., 11: 1171-1176.

Ik-Soo, A. and B. Myung-Jin, 2016. Study on a new sound necklace for a body fitness. Intl. Inf. Inst. Tokyo J. Inf., 19: 3737-3744.

Jae-Chu, J., K. Seung-Chul, C. Jung-Kwon and K. Tae-Jin, 2007. A basic study on the prevention of driving sleepiness of vehicle drivers. J. Veh. Eng., 1: 140-145.

Ji-Seon, H. and B. Myung-Jin, 2013. A study on the classic music for stress reduction. Proc. Acoust. Soc. Korea Conf., 32: 64-65.

Jung, K.M., 2017. Fire Protection Theory. DongHwa Technology Publishing Co., Korea,

Kang, Y.H., 2008. Encyclopedia of Life Science. Academybook Publisher, Seoul, Korea,.

Kim, J.H., H.S. Bae and S.S. Park, 2016. The effects of breath-counting meditation and deep breathing on heart rate variability. J. Korean Med., 37: 36-44.

Kyoung-Su, Y., P. Sun-Young and B. Myoung-Jin, 2016. A study of acoustic suppression of flame. Conf. Voice Commun. Signal Process. Acoust. Soc. Korea, 32: $170-171$.

Lee, P.S., 1999. Theoretical bases and technical application of breathing therapy in stress management. J. Korean Acad. Nurs., 29: 1304-1313.

Myung-Jin, B., 2017. On a voice health technology. J. Acoust. Soc. Korea, 34: 3-4.

Sang-Hwi, J., P. Hyung-Woo and B. Myung-Jin, 2017. A study on reduction of digestion temperature of sonic fire extinguisher. Convergence Res. Lett. Multimedia Serv. Convergent Art, Hum. Soc., 3: 1457-1460.

Sang-Hyuk, P. and Y. Chang-Dong, 2011. Efficient real-time drowsy detection algorithm for safe operation. Conf. Electron. Eng. Soc. Korea, 6: 947-950.

Seal, B., 2012. Academic Encounters: Human Behavior. Cambridge University, Cambridge, England, UK., 